\title{
Is there an immune modulating role for follicular fluid in endometriosis? A narrative review
}

\author{
Jelmer R Prins, Lotte M Marissen, Sicco A Scherjon, Annemieke Hoek and Astrid E P Cantineau \\ Department of Obstetrics and Gynaecology, University of Groningen, University Medical Center Groningen, \\ Groningen, The Netherlands \\ Correspondence should be addressed to J R Prins; Email: j.r.prins@umcg.nl
}

\begin{abstract}
Follicular fluid (FF) surrounds the granulosa cell-oocyte complex and is one of the mediating factors in the communication between the cells within the follicle. Literature reveals that human FF and its components are key factors to the success of natural fertilization. Among other substances, FF consists of multiple cytokines and immune cells, including interleukin 6 (IL6), IL12, sHLA-G, macrophages, NK cells and lymphocytes. Together, these cells and cytokines might influence the oocyte-granulosa-cell complex. Altered balances of immune content might be involved in changes on folliculogenesis, oocyte maturation, oocyte quality and ovulation. Furthermore, these altered balances are possibly involved in infertility associated with immune-mediated diseases such as endometriosis. The aim of this narrative review is to elaborate on the function and contents of FF and its immunological profile in patients with endometriosis. A comprehensive literature search was performed for the published literature on FF (immune) contents, FF function and FF content alterations in endometriosis patients. In FF of patients with endometriosis, elevated levels of macrophages and several cytokines have been reported. The role of specific immune cells in FF and a clarification of the biological mechanism in healthy women and endometriosis patients remain largely unknown. Future studies in this field will give us more insight in the role of FF immune cells and the effect of altered balances in patients with endometriosis.
\end{abstract}

Reproduction (2020) 159 R45-R54

\section{Introduction}

Follicular fluid (FF) is an important component in the growth and development of the follicle. Therefore, changes in FF will influence the developing oocyte (Hennet \& Combelles 2012). FF consists of many substances, such as hormones, immune cells, cytokines, enzymes, anticoagulants, electrolytes, reactive oxygen species, lipids, cholesterol and antioxidants (Hennet \& Combelles 2012, Nagy et al. 2015, Basuino \& Silveira 2016).

Endometriosis is a disorder characterized by the presence and growth of endometrial tissue outside the uterine cavity (Kennedy et al. 2005). The most accepted theory on the origin of endometriosis is Sampson's theory of retrograde menstruation (Sampson 1927, Izumi et al. 2018). Research has demonstrated retrograde menstruation in most menstruating women (Ahn et al. 2015). However, additional factors are essential to allow implantation and proliferation of endometrial cells and the development of endometriosis since clinical detected endometriosis only affects up to $10 \%$ of women in the reproductive age. In short, the clearance of endometrial debris in the peritoneal cavity is decreased in women with endometriosis, due to defective natural killer (NK) cell function, decreased phagocytosis by macrophages and induction of regulatory T cells (Zhang et al. 2018).
Together, these factors may contribute to the tolerance of endometrial cells in the peritoneal cavity.

The peritoneal fluid (PF) in women with endometriosis is also marked by increased inflammation, including increased concentrations of leukocytes and cytokines secreted by ectopic endometrial cells and infiltrating immune cells. This promotes endometrial cell proliferation, endometrial cell adhesion and angiogenesis (Zhang et al. 2018). Changes of the immune response detected in the peritoneal cavity can also be seen in uterine endometrial tissue, peripheral blood and FF (Zhang et al. 2018).

The immunological profile of $\mathrm{FF}$ in patients with endometriosis could be a reflection of the immunological changes in the systemic circulation or alternatively a reflection of local inflammation due to endometriosis lesions in the ovary or peritoneal cavity (de Barros et al. 2017). Furthermore, FF is a contributor to the PF at ovulation (Bahtiyar et al. 1998). Interestingly, FF was found to stimulate the proliferation of ectopic endometrial cells in vitro and therefore repetitive exposure to FF during ovulation may be involved in the enhancement of peritoneal endometriosis (Bahtiyar et al. 1998). Lower fecundity in women with endometriosis is attributed to anatomic alterations such as adhesions leading to disturbed folliculogenesis and ovum pick-up 
mechanisms (Somigliana et al. 2017). Also involved in the lower fecundity in endometriosis is the trafficking of leukocyte subsets to the eutopic endometrium due to inflammatory changes. The specific chemokines that direct their migration and the inflammatory changes could have detrimental effects on endometrial receptivity, possibly via progesterone resistance and changes in endometrial gene expression (Lessey et al. 2013). Our hypothesis is that the altered systemic and local peritoneal immune profile in endometriosis patients has its effects on the endometrium/decidua in the uterus. And furthermore on FF surrounding the maturing oocyte which both might lead to a reduced fecundity independent of the anatomical changes such as adhesions.

The aim of this narrative review is to summarize literature on the most prominent immune cells in the FF in the general infertile population and in patients with endometriosis. The key points relevant to FF immune cells and cytokines in reproductive outcomes and endometriosis that emerge from this review are listed in Box 1.

\section{Methods}

A comprehensive literature search was performed in the PubMed database for published literature on FF immune content, FF functions and FF composition in patients with and without endometriosis. We undertook a search on all literature published between 1990 and March 2019. English was used as language restriction. Relevant articles were identified by searching for (combinations of) search terms such as FF, endometriosis, cytokine, immunology, interleukin, $\mathrm{T}$ cell, B cell, lymphocyte, macrophage, antigen-presenting cell and NK cell. Additional studies were identified by analysis of reference lists. Data from studies were analyzed, interpreted and are presented in this review.

Box 1 Key features of FF immune cells and cytokines

- Human FF is an important factor present in every stage of conception

- High levels of CD56 ${ }^{\text {bright }} \mathrm{CD} 16^{-}$NK cells in FF are associated with good reproductive outcomes

- High levels of CD56 ${ }^{\mathrm{dim}} \mathrm{CD} 16^{+} \mathrm{NK}$ cells in FF are associated with adverse reproductive events

- sHLA-G levels in FF are not a marker for good-quality oocytes

- High levels of IL1B in FF are associated with good fertilization rates

- Elevated levels of IL12 in FF are detrimental to reproductive success in IVF

- In patients with endometriosis, NK cell levels in FF are higher compared to controls

- In patients with endometriosis, CD14+ macrophages/ monocytes levels in FF are higher compared to controls

- In patients with endometriosis, IL6, IL8 and IL12 levels in FF are higher compared to controls

Reproduction (2020) 159 R45-R54

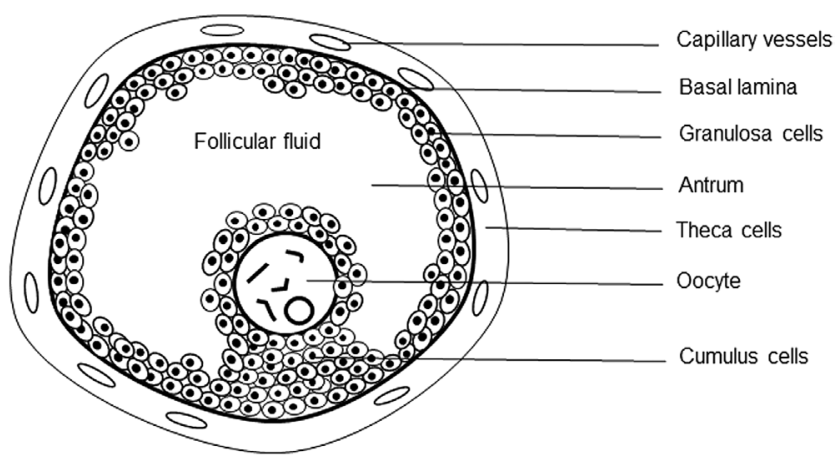

Figure 1 Schematic representation of an antral follicle with follicular fluid.

\section{Results}

\section{Human FF}

In antral follicles the oocyte undergoes a process of growth and maturation, to reach the optimal maturation stage for fertilization. This process occurs through a dynamic relationship between the oocyte within the antral follicle, consisting of granulosa and theca cells separated by the basement membrane (Fig. 1) (Hennet \& Combelles 2012). During follicle growth an antrum is formed and filled with FF. FF is a combined product of those blood plasma constituents that cross the blood follicular barrier, and the granulosa and thecal cells' secretory activity (Gosden et al. 1988). The follicular microenvironment in which the oocyte matures is also influenced by the oocyte itself, through gap junctional communication and secreted factors within the oocyte-cumulus complex (Gilcrist et al. 2008). FF consists of hormones, immune cells, cytokines, enzymes, anticoagulants, electrolytes, reactive oxygen species, lipids, cholesterol and antioxidants. Likely, immune cells secrete products in the FF as well (Fig. 1) (Hennet \& Combelles 2012, Nagy et al. 2015, Basuino \& Silveira 2016).

The composition of FF varies throughout the phases of follicular development (Baskind et al. 2014). It is postulated that during the follicular phase, the basement membrane is intact, thereby preventing exchange from the theca cell compartment to the avascular granulosa cell compartment (Duffy et al. 2019). When the luteal surge occurs, the basement membrane ruptures, causing vascular changes within the follicle resulting in invasion of capillaries with influx of various cells into the FF (Baskind et al. 2014). The phases of follicular development are therefore relevant when reviewing FF composition and function. However, literature on FF composition does not always report these phases. Furthermore, hyper-stimulation in ART alters FF contents as well. Using immunohistochemical analysis, it has been shown for example that levels of $\mathrm{CD} 45^{+}$leucocytes were significantly higher in FF from stimulated IVF compared to FF from natural cycle IVF (Kollmann et al. 2017). When using flow cytometry to further characterize 
the difference in $\mathrm{CD} 45^{+}$cells, no statistically significant differences were found in percentages of $\mathrm{CD}^{+}, \mathrm{CD}^{+}$, $\mathrm{CD}^{+}$and $\mathrm{CD} 19^{+}$cells, showing that it is not a subsetspecific increase (Kollmann et al. 2017).

\section{Immunological substances in human FF}

FF consists of several immune cell subsets and cytokines. Within FF immune cells such as NK cells, T- and B lymphocytes, dendritic cells (DCs) and macrophages have been found (Lachapelle et al. 1996, Takaya et al. 1997, Fainaru et al. 2012). In general, most studies use pre-ovulatory FF collected during IVF cycles with ovarian hyperstimulation for their analyses. The origin of FF leukocytes and cytokines in general is hard to determine, due to (some) contamination of the aspirate with blood during oocyte harvesting, collected after the induced LH surge or hCG injection. One study has examined leukocytes and erythrocyte levels within peripheral blood and follicular aspirate in patients with male factor infertility undergoing controlled ovarian hyperstimulation. This study reported that leukocytes appear independently of erythrocytes in follicular fluid, which indicates that active infiltration into FF takes place. It is unknown whether this infiltration is before or after the hCG administration which induces the final maturation of the oocyte in IVF (Smith et al. 2005). In the following sections of this review, we will summarize the literature on immune cells - and the interaction between these cells and cytokines - in FF and in endometriosis-related alterations in FF.

\section{NK cells in human FF}

NK cell subsets are distinguished phenotypically and functionally by their CD56 and CD16 surface antigen expression (Fainaru et al. 2011). The CD56 $6^{\mathrm{dim}} \mathrm{CD} 16^{+}$ and $\mathrm{CD} 56^{\text {bright }} \mathrm{CD} 16^{+} \mathrm{NK}$ cell subsets are cytotoxic, whereas the $\mathrm{CD} 56^{\text {bright }} \mathrm{CD} 16^{-} \mathrm{NK}$ cell subset has a more immune regulatory and pro-angiogenic function. One study measured levels of the pro-angiogenic $\left(\mathrm{CD} 56^{\text {bright }} \mathrm{CD} 16^{-}\right)$and cytotoxic $\left(\mathrm{CD} 56^{\mathrm{dim}} \mathrm{CD} 16^{+}\right) \mathrm{NK}$ cells in the FF of antral follicles $(<10 \mathrm{~mm})$, collected $38 \mathrm{~h}$ after hCG injection in patients with PCOS $(n=8)$ and patients with a contraindication for hormonal therapy $(n=2)$ (endometrial and breast carcinomas) in the context of in vitro maturation (IVM). This was compared with levels of NK cells in the FF of mature follicles $(>18 \mathrm{~mm})$, collected $34 \mathrm{~h}$ after hCG injection during IVF treatment in patients with an infertility diagnosis (male, unexplained, tubal). The distribution of NK cell subpopulations in FF derived from an antral follicle of IVM patients revealed a predominance of cytotoxic $\mathrm{CD}_{56} 6^{\mathrm{dim}} \mathrm{CD} 16^{+}$and $\mathrm{CD} 56^{\text {bright }} \mathrm{CD} 16^{+} \mathrm{NK}$ cell in the antral follicle compared to mature follicles (Fainaru et al. 2011). The infertility diagnoses in each group (IVM versus IVF) were different, which might introduce a difference in the reported distribution of
NK cell subpopulations. This could be due to an altered immune profile of the various diagnostic categories of the patients instead of the maturity of the follicles. Krizan and colleagues reported that the relative distribution of $\mathrm{CD} 56^{\text {bright }} \mathrm{CD} 16^{-}$immune regulatory NK cells in $\mathrm{FF}$ was significantly higher in patients after a successful IVF treatment resulting in a pregnancy, compared with a negative outcome (Krizan et al. 2009). On the other hand, higher levels of the $\mathrm{CD} 56^{\mathrm{dim}} \mathrm{CD} 16^{+}$cytotoxic NK cells in FF from IVF patients with unexplained infertility compared with a control group, consisting of patients with male factor infertility, are associated with diminished fertilization rates. The balance between angiogenic and cytotoxic NK cell subsets in the developing follicle might contribute to maturation of the cumulus-oocyte complex and the final goal of achieving a pregnancy. However, the functional role of these cells was not determined (Lukassen et al. 2003).

\section{Macrophages in human FF}

The presence of macrophages in FF, obtained after hCG injection during IVF cycles with ovarian hyperstimulation, are described in several studies (Lachapelle et al. 1996, Smith et al. 2005). Macrophages can be classified into different functional subsets, with specific roles in vascularization, tissue remodeling and inflammation (Wu et al. 2004, Sica \& Mantovani 2012). However, only total macrophage fractions have been studied and to our knowledge macrophage subsets in FF have not yet been analyzed in humans. Brannstrom et al. (1994) found elevated macrophage density in the infiltrate of the thecal layer of the human follicle wall immediately after the LH surge. Takaya et al. (1997) analyzed macrophage levels in normal human ovulating cycles and reported lower macrophage infiltration in the stroma and theca cell layer in developing follicles as compared to corpora lutea. Wu et al. (2004) proposed that ovarian macrophages stimulate theca and granulosa cell proliferation, follicle growth and suppress follicular apoptosis, by secreting growth factors and cytokines. Ovarian macrophages secrete growth factors like epidermal growth factor (EGF) and insulin-like growth factors (IGFs), granulocyte macrophage-colony stimulating factors (GM-CSF) as well as cytokines such as IL1B, IL1, IL6, IL10, IL12, IFNa and TNFa (Wu et al. 2004). Cytokine profiles in FF will be further discussed in 'Cytokines in human FF'. To our knowledge, there are no studies describing the macrophage levels in human FF in the different follicular phases despite their presumed relevance in cytokine production.

\section{Human leukocyte antigen (HLA)-G in human FF}

HLA-G is a non-classical HLA-class Ib molecule from the major histocompatibility complex.

Despite the presence of soluble HLA-G1 (sHLA-G) and sHLA-G5 in FF, the role of intrafollicular sHLA-G 
molecules remains largely unknown (Shaikly et al. 2008, Jee et al. 2011, Ouji-Sageshima et al. 2016). Granulosa cells are identified as the primary source of sHLA-G in FF, but sHLA-G could also emanate from peripheral circulation, possibly during oocyte harvesting (Shaikly et al. 2008, Rizzo et al. 2009). Several studies have investigated HLA-G as a marker for oocyte quality and implantation potential. Studies showed an inverse correlation between sHLA-G levels in FF and oocyte quality, reflected by fertilization rate, but no association with successful pregnancy (Jee et al. 2011, OujiSageshima et al. 2016).

\section{$T$ and $B$ lymphocytes and subpopulations in human FF}

The presence of $\mathrm{T}$ and $\mathrm{B}$ subsets in FF has been described in several heterogeneous groups of infertile patients with different indications and comparing stimulated IVF with natural cycle IVF using markers as CD3, CD4, CD8, CD14, CD15, CD19, CD20, CD27, CD45 and CD57 (Hill et al. 1989, Lachapelle et al. 1996, Vujisic et al. 2004, Wu et al. 2007, Qin et al. 2016, Kollmann et al. 2017). However, the function of these cells in FF remains largely unknown. As $\mathrm{CD}^{+} \mathrm{T}$ cells can be divided in Th1, Th2, Th17 and Treg subsets (Guerin et al. 2009, Wan et al. 2010), which all have their specific function, future studies analyzing these subsets in FF in more detail related to the outcome of IVF are needed.

\section{Cytokines in human FF}

Cytokines are small-molecular-weight glycoproteins that act as intercellular mediators across various immune effector cells, ovarian somatic cells and the oocyte (Vujisic \& Zidovec 2005, Baskind et al. 2014). The following cytokines have been found in FF: IL1a and IL1B, IL2, IL6, IL8, IL10, IL11, IL12, IL13, IL17A, IL18, IL23, granulocyte- colony stimulating factor (G-CSF), granulocyte macrophage colony-stimulating factor (GM-CSF), macrophage colony-stimulating factor (M-CSF), TNFa, vascular endothelial growth factor (VEGF), EGF, platelet-derived growth factor (PDGF), IGF, leukemia inhibitory factor (LIF), fibroblast growth factor (FGF), RANTES (CCL5) and stem cell factor (SCF) (Vujisic \& Zidovec 2005, Sabbaghi et al. 2014). Many cytokines have been found in FF, in the current review, we have focused on those cytokines which are mainly reported in FF of patients with endometriosis. Below we briefly describe these cytokines.

TNFa is a pro-inflammatory cytokine released by macrophages and its production can be induced by VEGF. It has a role in proliferation of granulosa cells and enhances its IL8 secretion (Kilic et al. 2007, Opøien et al. 2013). TNFa level is significantly higher in FF associated with poor quality oocytes and embryos (Wunder et al. 2006).
VEGF is a mediator that helps folliculogenesis and formation of the corpus luteum by stimulating ovarian angiogenesis, and it can be secreted by granulosa cells. Intrafollicular VEGF concentrations have no predictive value to evaluate IVF treatment outcome (Kilic et al. 2007).

IL1B is a pro-inflammatory cytokine that stimulates proliferation and activation of $\mathrm{T}$ and $\mathrm{B}$ cells, this cytokine is mainly produced by macrophages and monocytes. In the thecal cell layer of the human ovarian follicle, the presence of IL1B has been described, and an increase of intrafollicular IL1B at the time of ovulation is seen (Brannstrom et al. 1994). Furthermore, IL1B induces granulosa cell and theca cell IL6 and IL8 production (Baskind et al. 2014). In IVF patients, high levels of IL1B in FF were associated with good fertilization rates (Zollner et al. 2013). There is no correlation between FF IL1B levels and embryo morphology or pregnancy rates. Also, IL1B levels show no variation in FF concentrations during follicular development.

IL6 is not only produced by macrophages, Th1 cells and B cells, but also by fibroblasts and endothelial cells (Cameron \& Kelvin 2003). The expression of IL6 has been described in the granulosa cells of the follicle, the corpus luteum, ovarian theca cells, the endometrium and in the preimplantation embryo (Altun et al. 2011). IL6 affects the vascular permeability (Bergqvist et al. 2001) and angiogenesis (Kawasaki et al. 2003) during follicular growth and development of the oocyte. Moreover, IL6 has effects on most immune cells including B and T cells (Hunter \& Jones 2015).

IL6 in FF is significantly increased in the peri-ovulatory phase as compared to the follicular phase Baskind et al. (2014). Contradictory results exist on the possible effects of IL6 on IVF outcome. IL6 levels in FF were significantly higher in pregnant compared to non-pregnant IVF treated women (Bedaiwy et al. 2007). In contrast to these findings, another study reported detrimental effects of elevated FF IL6 levels on the outcome of IVF. Patients with IL6 levels in FF lower than the median were twice as likely to achieve clinical pregnancy as patients with higher IL6 levels (Altun et al. 2011). Both studies included comparable patients, but Bedaiwy et al. (2007) only performed univariate analysis, whereas Altun et al. (2011) did multivariate analysis including duration of $\mathrm{COH}$, FF IL6 level and the number of embryos transferred, which could explain different results. The latter study used group medians for statistical analysis, but in the final statistical model included a FF IL6 cut-off level of $<4.0 \mathrm{pg} / \mathrm{mL}$ as the independent variable. IL 6 cutoffs could possibly be more reliable.

IL8 is a pro-inflammatory cytokine secreted by granulosa cells and involved in the recruitment and activation of neutrophils as well as cell proliferation and angiogenesis, and with that likely important in folliculogenesis, ovulation and repair of the ruptured 
follicle (Vujisic \& Zidovec 2005). In FF, significantly higher levels of IL8 were found in the pre-ovulatory phase and LH surge, as compared to the follicular phase, both in natural cycles and stimulated cycles (Baskind et al. 2014). Therefore, it is thought that granulosa cell and theca cell IL8 secretion is associated with follicle growth, oocyte maturation and ovulation, rather than being solely the result of hormonal stimulation (Runesson et al. 2000). IL8 seems to vary inversely with IL10, IL12 and TNFa, indicating that immune cells may interact with granulosa cell function (Opøien et al. 2013). IL8 levels in FF are not associated with fertilization and implantation rates or IVF outcome (Gazvani et al. 2000).

IL12 is a pro-inflammatory cytokine that regulates the immune system as an inductor of Th1 response and regulator of biological activities of T cells and NK cells (Gazvani et al. 2000). IL12 levels are significantly higher in FF of women who failed to become pregnant with IVF (Gazvani et al. 2000, Bedaiwy et al. 2007, Altun et al. 2011). High levels of IL12 may represent an increased inflammatory state of the maternal immune system and with that lower pregnancy success.

RANTES (CCL5) is a chemokine, widely expressed in tissue and a potent monocyte, macrophage, $\mathrm{T}$ lymphocyte and eosinophil attractant. The regulation of RANTES can reflect local modulation of the immune system together with MCP-1 (Xu et al. 2006).

Many studies have focused on the analysis of the individual number of cytokines, despite the fact that these mediators are known to operate in networks rather than in isolation, exhibiting features such as pleiotropism, synergy, antagonism and functional redundancy. It follows that the effect of any given cytokine is therefore not just dependent upon its absolute concentration, but rather on a balance between its own effects and those induced by other local mediators, including other cytokines (Field et al. 2014).

\section{Dendritic cells in human FF}

Dendritic cells (DC) initiate and coordinate innate and adaptive immune responses. After maturation, DCs migrate into lymph nodes, where interaction with antigen-specific $T$ cells takes place to evoke an immune response (Fainaru et al. 2012). Following activation, DCs produce cytokines such as IL6, IL23 and TNFa. DCs function as a bridge between pathogen recognition and effector cells of both the innate and adaptive immunity (Sallusto 2013). DCs are a significant part of the bone marrow-derived leukocytes in the FF of the maturing oocyte immediately before ovulation, making up to $15 \%$ of the FF content of these cells (Fainaru et al. 2012). In patients undergoing IVF treatment DCs are present in pre-ovulatory FF and are characterized by expression of CD11c and HLA-DR. DC maturation correlates positively with the ovarian response to gonadotropins, but correlations between immune parameters in FF and oocyte quality, pregnancy outcomes are not reported (Fainaru et al. 2012, Zhang et al. 2017a).

\section{Alterations of immune cells in patients with endometriosis}

Our hypothesis is that the altered systemic and peritoneal immune profile in endometriosis patients has its effects on the endometrium/decidua in the uterus, as well as on FF surrounding the maturing oocyte. Both could possibly lead to a reduced fecundity due to an imbalanced immune profile, where a balanced profile is required for the maturing cumulus-oocyte complex in the follicles (Fig. 2).

\section{NK cells in FF of patients with endometriosis}

In patients with superficial peritoneal endometriosis (stage I/II) undergoing IVF treatment, higher levels of NK cells have been reported in FF compared to patients without endometriosis. Approximately $20 \%$ of CD $56^{+}$NK cells expressed CD16, which indicates that the increase in NK cells was caused predominantly by the proangiogenic NK subset (CD16-) (Lachapelle et al. 1996). Endometriosis is an angiogenesis dependent condition; thus, it is not surprising that there is an abundance of proangiogenic NK cells. In light of these results, modifications in the distribution of immune cell populations in the FF of patients with endometriosis likely influence the follicular environment and could subsequently influence folliculogenesis and cumulus-oocyte maturation. The cellular immune dysregulation in human ovaries could

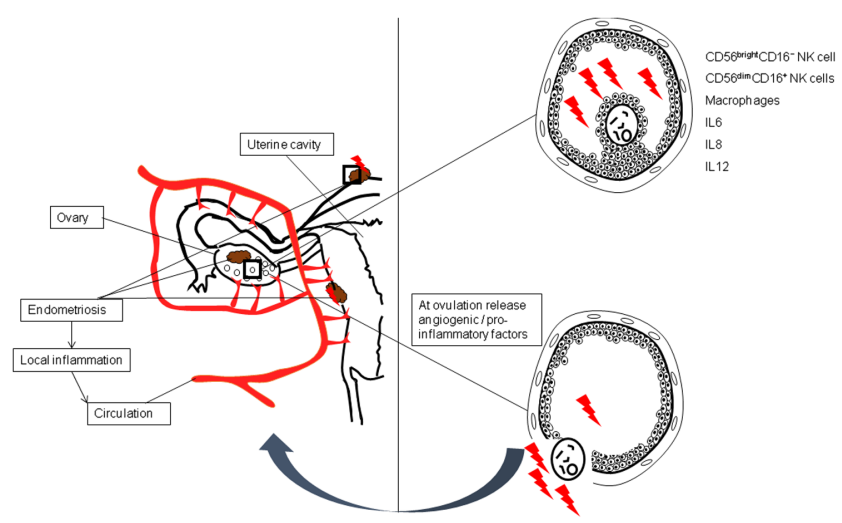

Figure 2 Schematic representation of immunological follicular fluid (FF) alterations in endometriosis patients and suggested role of FF in endometriosis and its associated infertility. A tolerogenic immune balance together with invasiveness of endometrial cells causes endometriosis lesions after retrograde menstruation. The endometriosis lesions cause local inflammation. Release of inflammatory factors through the circulation into the ovary causes alterations in follicular fluid contents. At ovulation, these factors are released into the peritoneal cavity. The pro-angiogenic factors stimulate endometriosis lesions. Furthermore, these factors are involved in the infertility associated with endometriosis. FF, follicular fluid; IL, interleukin; NK, natural killer. 
be a factor altering fertility. The presence of $\mathrm{CD} 56^{+} \mathrm{CD} 16^{-}$ pro-angiogenic NK cells has been associated with successful implantation, favorable IVF outcome, spiral artery remodeling and placental maturation (Fainaru et al. 2010). However, higher levels of these proangiogenic NK cells in FF of endometriosis patients are likely related to endometriosis itself and any positive effects on placentation will be too small to compensate for the higher inflammatory state in the endometrium. The pro-angiogenic NK cells in FF released during ovulation could create a certain peritoneal environment stimulating the development of peritoneal endometriosis, which in turn creates an even more inflammatory environment and with that compromised fecundity.

\section{Macrophages in FF of patients with endometriosis}

Macrophages are among the first immune cells to be recruited when endometrial fragments enter the peritoneal cavity. Compared to women without endometriosis, in women with endometriosis, the number of peritoneal macrophages, the activation status and the concentration of inflammatory cytokines (i.e. IL1B, IL6, TNFa) secreted by these macrophages are elevated (Wunder et al. 2006). By secreting these proinflammatory cytokines, macrophages may promote the establishment of an inflammatory environment favorable for endometriosis development.

In patients with endometriosis (stage I/II), compared with groups of idiopathic infertility and tubal factor, flow cytometric evaluation in FF revealed higher levels of $\mathrm{CD}_{14}{ }^{+}$macrophages/monocytes which could lead to altered cytokine levels, leading to dysregulation of folliculogenesis and thereby impacting fertility (Lachapelle et al. 1996). These $\mathrm{CD}_{14}{ }^{+}$cells were not further characterized into macrophage or monocyte subsets.

Many macrophage-derived cytokines, such as IL1B and IL6, are increased in the FF of patients with endometriosis, indicating strong macrophage activity in FF, which may contribute to the pathogenesis of endometriosis (Pellicer et al. 1998, Tsudo et al. 2000, Wu et al. 2004).

Although higher levels of $\mathrm{CD}^{+} 4^{+}$macrophages/ monocytes in FF of endometriosis patients have been found, to our knowledge, these levels have not been further characterized into specific subsets. Therefore, it is difficult to interpret the exact role of these higher FF levels of macrophages in endometriosis and its associated fertility problems. More research is needed to determine the differences in peritoneal and FF macrophage subsets and the effects on folliculogenesis, maturation of the oocyte or oocyte quality and the involvement in the pathophysiology of endometriosis.

\section{HLA-G in FF of patients with endometriosis}

sHLA-G has been demonstrated to induce apoptosis of activated $\mathrm{CD}^{+} \mathrm{T}$ cells and to modulate the NK cell and cytotoxic T lymphocyte responses, whereas membranebound HLA-G proteins have been shown to inhibit both natural killer cell and T cell-mediated cytolysis, to suppress proliferation of $\mathrm{CD}^{+} \mathrm{T}$ lymphocytes and to induce a Th2 cytokine profile (Eidukaite \& Tamosiunas 2008). In endometriosis, HLA-G was found in ectopic endometrial cells in the peritoneal cavity in women which is postulated to aid in their escape from immunosurveillance, due to their role in the protection against NK cell-mediated lysis (Barrier et al. 2006, Kawashima et al. 2009, Rached et al. 2019).

Eidukaite and Tamosiunas compared PF sHLA-G concentrations between endometriosis patients and controls. sHLA-G was found in all groups investigated without significant differences in concentrations (Eidukaite \& Tamosiunas 2008). Rached et al. assessed sHLA-G levels in serum and PF in women with and without endometriosis. Higher concentration of sHLA-G in serum but not in the PF were observed in women with advanced endometriosis compared to the control group (Rached et al. 2019). Binding of the sHLA-G to inhibitory receptors on immune cells might explain the non-significant lower concentrations in SHLA-G available in PF between women with and without endometriosis (Rached et al. 2019). Mach et al. compared the blood sera among patients with ovarian cancer, ovarian endometrioma and deep endometriosis. The HLA-G concentration levels in the patients with deep endometriosis were comparable to those found in the patients with ovarian cancer, in contrast to significantly lower levels found in patients with ovarian endometrioma (Mach et al. 2010). HLA-G was furthermore found in ectopic endometrial cells in the peritoneal cavity in women which is postulated to aid in their escape from immunosurveillance due to their role in the protection against NK cell-mediated lysis (Barrier et al. 2006, Kawashima et al. 2009, Rached et al. 2019). To our knowledge, no studies have been published yet on SHLA-G levels in FF of patients with endometriosis.

\section{$T$ and $B$ cells in FF of patients with endometriosis}

Changes in the adaptive immune responses ( $T$ and $B$ lymphocytes) have been described in the endometrium, $\mathrm{PF}$ and peripheral blood of patients with endometriosis, compared to women without this disorder (Podgaec et al. 2012, Olkowska-Truchanowicz et al. 2013, Ahn et al. 2015). Studies showed a balance toward Th2 cytokines in peripheral blood and PF of women with endometriosis (Hsu et al. 1997). This shift toward a Th2 immune response was confirmed by Podgaec et al., who found elevated IL4, IL10 and IFN-gamma levels in the PF of patients with endometriosis compared to those without endometriosis (Podgaec et al. 2007).

A subset of cells which is involved in the immune processes in endometriosis are regulatory $\mathrm{T}$ cells (Tregs). These are specialized $\mathrm{T}$ lymphocytes with 
immunosuppressive properties (Guerin et al. 2009, de Barros et al. 2017). Several studies have found Treg cell concentrations to be higher in the peripheral blood, PF and eutopic endometrium in patients with endometriosis, compared to patients without endometriosis (Podgaec et al. 2012, Olkowska-Truchanowicz et al. 2013). Although it seems logical that the higher levels of Treg cells are involved in the immune tolerance of the endometriotic lesions, this has not been fully elucidated yet.

Similar to other specific cell subsets of T and B cells, there is not much known about Treg cells in FF. One study showed that patients with endometriosis have higher levels of B cells, and comparable levels of T cells in FF compared to groups with other infertility causes (Lachapelle et al. 1996). However, to our knowledge, no further analysis of $\mathrm{T}$ and $\mathrm{B}$ cell subsets in FF have been done in patients with endometriosis. Therefore, no conclusions can be made yet about possible correlations between T and B cells in FF, endometriosis and the effect on folliculogenesis, oocyte maturation and infertility.

\section{Cytokines in FF of patients with endometriosis}

Singh et al. (2016) reported an increase in the levels of pro-inflammatory (IL1B, TNFa, IL2, IL8, IL12) and anti-inflammatory (IL4, IL6 and IL10) cytokines in FF of patients with endometriosis (grade III/IV) undergoing IVF as compared with patients with tubal factor infertility (Box 2). The percentage of mature oocyte and goodquality embryos was significantly lower in endometriosis as compared with controls. Part of these findings were confirmed by Choi et al. (2015) who also reported higher levels of IL6, IL8, TNFa and IL1B in FF of endometriosis patients (Choi et al. 2015). Whereas Falconer et al. (2009) found lower levels of IL10 in FF of endometriosis patients (Falconer et al. 2009). Pellicer et al. (1998) reported significantly higher IL6 and higher, but not statistically significant, IL1B levels in FF of patients with endometriosis (grade III/IV) undergoing IVF as compared with patients with tubal factor infertility. Zhang et al. also analyzed cytokines in women with severe endometriosis (grade III/IV), although they did not find a difference in these cytokines between the control and grade III/IV endometriosis patients, IL23 levels in FF were significantly higher in patients with stage III/IV endometriosis compared to stage I/II (Zhang et al. 2017b).

The results of the study by Pellicer et al. were confirmed in the study of Wu et al. (2017) in natural cycle IVF in women with moderate-to-severe endometriosis. On the other hand, Opøien et al. (2013) found no difference in cytokine levels (IL1B, IL6, IL8, IL10, IL12 and TNFa) in the leading follicle adjacent to endometriomas. These results suggest that intra-ovarian endometriosis itself is not associated with local inflammatory reaction.

Furthermore, Kilic et al. (2007) compared VEGF and TNFa concentrations in FF of patients with endometriosis and unexplained infertility and reported a significant higher concentration VEGF in the endometriosis group but no difference in TNFa concentration between the two groups. The levels of RANTES and MCP-1 (both chemokines) have also been analyzed in FF of endometriosis patients, Xu et al. (2006) have shown higher levels of RANTES and lower levels of MCP-1 in FF of women with endometriosis compared with tubal infertility (Xu et al. 2006).

These altered levels of cytokines, including chemokines, could very well be a result of the increased inflammatory state in endometriosis. Moreover, these levels in turn could attract more immune cells into the follicle or into the peritoneal cavity after ovulation. Differences in patient characteristics and methods used can explain the sometimes contradicting results. Although both pro- and anti-inflammatory cytokines have been found higher in FF of endometriosis patients, the balance of these elevated cytokines indicated a pro-inflammatory environment, which confirms the inflammatory character of endometriosis.

Altered cytokine profiles in the FF of patients with endometriosis may play a significant role in an altered folliculogenesis, oocyte maturation, oocyte quality, ovulation and fecundity associated with endometriosis. Possibly, the higher levels of FF cytokines are produced by the granulosa cells or the FF immune cells which might be more activated in endometriosis. However, the activity of these FF immune cells is yet to be analyzed in endometriosis patients (Wu et al. 2017).

\begin{tabular}{|c|c|c|c|}
\hline Cytokines & Origin & Function & Reference(s) \\
\hline IL1B & $\begin{array}{l}\text { Theca cells } \\
\text { Macrophages and monocytes }\end{array}$ & $\begin{array}{l}\text { Proliferation and activation of T and B cells } \\
\text { Induces IL } 6 \text { and IL8 production by granulosa cells }\end{array}$ & $\begin{array}{l}\text { Brannstrom et al. } \\
\text { 1994Baskind et al. } 2014\end{array}$ \\
\hline IL6 & $\begin{array}{l}\text { Macrophages, T cells, B cells } \\
\text { fibroblasts, endothelial cells }\end{array}$ & $\begin{array}{l}\text { Effect on vascular permeability } \\
\text { Angiogenesis } \\
\text { T cell differentiation, proliferation and survival } \\
\text { B cell maturation }\end{array}$ & $\begin{array}{l}\text { Bergqvist et al. } 2001 \text { Kawasaki } \\
\text { et al. } 2003\end{array}$ \\
\hline IL8 & Granulosa cells Theca cells & $\begin{array}{l}\text { Recruitment and activation of neutrophils, } \\
\text { cell proliferation and angiogenesis }\end{array}$ & Vujisic \& Zidovec 2005 \\
\hline IL12 & $\begin{array}{l}\text { B cells, phagocytic cells and } \\
\text { other antigen-presenting cells }\end{array}$ & $\begin{array}{l}\text { Inductor of Th1 response and regulator of } \\
\text { biological activities on T cells and NK cells }\end{array}$ & Gazvani et al. 2000 \\
\hline
\end{tabular}




\section{Dendritic cells in FF of patients with endometriosis}

In mouse models DCs have been shown to be important in the development of endometriosis. In humans the role of DCs in endometriosis is largely unknown (Pencovich et al. 2014, Stanic et al. 2014). Fainaru et al. (2012) described in one case an unilateral endometrioma which was associated with complete absence of DCs, contrary to a follicle of the contralateral ovary, where an abundance of DCs was seen. Another study reported lower levels of $\mathrm{HLA}_{-} \mathrm{R}^{+}, \mathrm{CD} 11 \mathrm{C}^{+} \mathrm{CD} 123^{+} \mathrm{DCs}$ in PF of patients with endometriosis compared to controls with no endometriosis; however, this did not reach statistical significance (Tariverdian et al. 2009). Further research is necessary on DCs presence and function in the FF of endometrsiosis patients to determine the effect on folliculogenesis, oocyte maturation, quality and fertility potential.

\section{Conclusion}

We hypothesized that the altered immune profile in endometriosis patients has its effects not only on the endometrium/decidua in the uterus, but also on FF surrounding the maturing oocyte both possibly leading to a reduced fecundity (Fig. 2). FF represents the microenvironment for the oocyte to develop optimally. FF is composed of many substances including immune cells and cytokines, all of which are likely to play a crucial role in maturing of the oocyte and implantation of the resulting embryo. The physiological role of the immune cells and cytokines in FF in the normal follicle is not yet determined. Therefore, the exact role and differences of FF in women with immune-mediated diseases such as endometriosis remain unknown.

In the PF, peripheral blood and endometrium of patients with endometriosis, multiple alterations have been found that possibly contribute to the establishment and development of the disease, such as impaired NK cell activity, reduced phagocytosis capacity of macrophages and elevated Treg concentrations. Increased quantities of peritoneal and follicular macrophages are held accountable for the secretion of many cytokines, which in turn might alter FF, thereby possibly influencing follicle maturation, oocyte development and quality. Although many studies have addressed FF macrophage, NK cell and cytokine quantity, activity and alterations in patients with endometriosis and compared to patients without endometriosis, the results are not conclusive. The effect of follicle fluid, released at ovulation, to the peritoneal cavity as a synergistic factor in the development of endometriosis also demand further exploration. While decidual $\mathrm{T}$ cells seem to play an important role in achieving a normal pregnancy, with an important role for Tregs, no studies so far have been undertaken to analyze these T cells in FF of women with endometriosis. Future studies in this field might give us more insight in the role of immune cells and cytokines in the mechanism of and the effects on the folliculogenesis, oocyte maturation, oocyte quality, ovulation and fecundity in patients with endometriosis. This knowledge might have a great impact in reducing infertility in endometriosis, by interfering with the immune cell and cytokine balance in FF.

\section{Declaration of interest}

The authors declare that there is no conflict of interest that could be perceived as prejudicing the impartiality of this review.

\section{Funding}

The Department of OBGYN received an unrestricted educational grant from Ferring Pharmaceutical Company BV The Netherlands, unrelated to the present manuscript.

\section{References}

Ahn SH, Monsanto SP, Miller C, Singh SS, Thomas R \& Tayade C 2015 Pathophysiology and immune dysfunction in endometriosis. BioMed Research International $2015 \quad 795976 . \quad$ (https://doi. org/10.1155/2015/795976)

Altun T, Jindal S, Greenseid K, Shu J \& Pal L 2011 Low follicular fluid IL-6 levels in IVF patients are associated with increased likelihood of clinical pregnancy. Journal of Assisted Reproduction and Genetics 28 245-251. (https://doi.org/10.1007/s10815-010-9502-8)

Bahtiyar MO, Seli E, Oral E, Senturk LM, Zreik TG \& Arici A 1998 Follicular fluid of women with endometriosis stimulates the proliferation of endometrial stromal cells. Human Reproduction 13 3492-3495. (https://doi.org/10.1093/humrep/13.12.3492)

Barrier BF, Kendall BS, Ryan CE\& Sharpe-Timms KL 2006 HLA-G is expressed by the glandular epithelium of peritoneal endometriosis but not in eutopic endometrium. Human Reproduction 21 864-869. (https:// doi.org/10.1093/humrep/dei408)

Baskind NE, Orsi NM \& Sharma V 2014 Follicular-phase ovarian follicular fluid and plasma cytokine profiling of natural cycle in vitro fertilization patients. Fertility and Sterility 102 410-418. (https://doi.org/10.1016/j. fertnstert.2014.04.032)

Basuino L \& Silveira CF 2016 Human follicular fluid and effects on reproduction. JBRA Assisted Reproduction 20 38-40. (https://doi. org/10.5935/1518-0557.20160009)

Bedaiwy M, Shahin AY, AbulHassan AM, Goldberg JM, Sharma RK, Agarwal A \& Falcone T 2007 Differential expression of follicular fluid cytokines: relationship to subsequent pregnancy in IVF cycles. Reproductive Biomedicine Online 15 321-325. (https://doi.org/10.1016/ S1472-6483(10)60346-X)

Bergqvist A, Bruse C, Carlberg M \& Carlstrom K 2001 Interleukin 1beta, interleukin-6, and tumor necrosis factor-alpha in endometriotic tissue and in endometrium. Fertility and Sterility 75 489-495. (https://doi. org/10.1016/s0015-0282(00)01752-0)

Brannstrom M, Pascoe V, Norman RJ \& McClure N 1994 Localization of leukocyte subsets in the follicle wall and in the corpus luteum throughout the human menstrual cycle. Fertility and Sterility 61 488-495. (https:// doi.org/10.1016/S0015-0282(16)56581-9)

Cameron MJ \& Kelvin DJ 2003 Cytokines and chemokines - their receptors and their genes: an overview. Advances in Experimental Medicine and Biology 520 8-32. (https://doi.org/10.1007/978-1-4615-0171-8_2)

Choi YS, Cho S, Seo SK, Park JH, Kim SH \& Lee BS 2015 Alterationin the intrafollicular thiol-redox system in infertile women with endometriosis. Reproduction 149 155-162. (https://doi.org/10.1530/REP-14-0438)

de Barros IBL, Malvezzi H, Gueuvoghlanian-Silva BY, Piccinato CA, Rizzo LV \& Podgaec S 2017 What do we know about regulatory T cells and endometriosis? A systematic review. Journal of Reproductive Immunology 120 48-55. (https://doi.org/10.1016/j.jri.2017.04.003) 
Duffy DM, Ko C, Jo M, Brannstrom M \& Curry TE 2019 Ovulation: parallels with inflammatory processes. Endocrine Reviews 40 369-416. (https://doi.org/10.1210/er.2018-00075)

Eidukaite A \&Tamosiunas V 2008 Soluble HLA-G in the peritoneal fluid of women with endometriosis. Fertility and Sterility 89 465-467. (https:// doi.org/10.1016/j.fertnstert.2007.02.036)

Fainaru O, Amsalem H, Bentov Y, Esfandiari N \& Casper RF 2010 CD56brightCD16- natural killer cells accumulate in the ovarian follicular fluid of patients undergoing in vitro fertilization. Fertility and Sterility 94 1918-1921. (https://doi.org/10.1016/j.fertnstert.2009.12.067)

Fainaru O, Hantisteanu S, Rotfarb N, Michaeli M, Hallak M \& Ellenbogen A 2011 Maturation of human ovarian follicles is accompanied by a decrease in the CD56+CD16+ natural killer cell population. Fertility and Sterility 95 2395-2398. (https://doi.org/10.1016/j.fertnstert.2011.03.012)

Fainaru O, Hantisteanu S, Rotfarb N, Michaeli M, Hallak M \& Ellenbogen A 2012 CD11c+HLADR+ dendritic cells are present in human ovarian follicular fluid, and their maturity correlates with serum estradiol levels in response to gonadotropins. Fertility and Sterility 97 702-706. (https:// doi.org/10.1016/j.fertnstert.2011.12.030)

Falconer H, Sundgvist J, Gemzell-Danielsson K, von Schoultz B, D'Hooghe TM \& Fried G 2009 IVF outcome in women with endometriosis in relation to tumour necrosis factor and anti-Mullerian hormone. Reproductive Biomedicine Online 18 582-588. (https://doi. org/10.1016/S1472-6483(10)60138-1)

Field SL, Dasgupta T, Cummings M \& Orsi NM 2014 Cytokines in ovarian folliculogenesis, oocyte maturation and luteinisation. Molecular Reproduction and Development 81 284-314. (https://doi.org/10.1002/ mrd.22285)

Gazvani MR, Bates M, Vince G, Christmas S, Lewis-Jones DI \& Kingsland C 2000 Follicular fluid concentrations of interleukin-12 and interleukin-8 in IVF cycles. Fertility and Sterility 74 953-958. (https://doi.org/10.1016/ s0015-0282(00)01538-7)

Gilcrist RB, Lane M \& Thompson JG 2008 Oocyte-secreted factors: regulators of cumulus cell function and oocyte quality. Human Reproduction Update 14 159-177. (https://doi.org/10.1093/humupd/dmm040)

Gosden RG, Hunter RH, Telfer E, Torrance C \& Brown N 1988 Physiological factors underlying the formation of ovarian follicular fluid. Journal of Reproduction and Fertility 82 813-825. (https://doi.org/10.1530/ jrf.0.0820813)

Guerin LR, Prins JR \& Robertson SA 2009 Regulatory T-cells and immune tolerance in pregnancy: a new target for infertility treatment? Human Reproduction Update 15 517-535. (https://doi.org/10.1093/humupd/ dmp004)

Hennet ML \& Combelles CM 2012 The antral follicle: a microenvironment for oocyte differentiation. International Journal of Developmental Biology 56 819-831. (https://doi.org/10.1387/ijdb.120133cc)

Hill JA \& Anderson DJ 1989 Distribution of T cell subsets in follicular fluid. Fertility and Sterility 51 736-737. (https://doi.org/10.1016/s00150282(16)60633-7)

Hsu CC, Yang BC, Wu MH \& Huang KE 1997 Enhanced interleukin-4 expression in patients with endometriosis. Fertility \& Sterility 671059 1064

Hunter CA\& Jones SA 2015 IL-6 as a keystone cytokine in health and disease. Nature Immunology 16 448-457. (https://doi.org/10.1038/ ni.3153)

Izumi G, Koga K, Takamura M, Makabe T, Satake E, Takeuchi A, Taguchi A, Urata Y, Fujii T \& Osuga Y 2018 Involvement of immune cells in the pathogenesis of endometriosis. Journal of Obstetrics and Gynaecology Research 44 191-198. (https://doi.org/10.1111/jog.13559)

Jee BC, Suh CS, Kim SH \& Moon SY 2011 Soluble human leukocyte antigen $\mathrm{G}$ level in fluid from single dominant follicle and the association with oocyte competence. Yonsei Medical Journal 52 967-971. (https:// doi.org/10.3349/ymj.2011.52.6.967)

Kawasaki F, Kawano Y, Kosay Hasan Z, Narahara H \& Miyakawa I 2003 The clinical role of interleukin- 6 and interleukin- 6 soluble receptor in human follicular fluids. Clinical and Experimental Medicine 3 27-31. (https://doi.org/10.1007/s102380300012)

Kawashima M, Maeda N, Adachi Y, Takeuchi T, Yamamoto Y, Izumiya C, Hayashi K, Furihata M, Udaka K \& Fukaya T 2009 Human leukocyte antigen-G, a ligand for the natural killer receptor KIR2DL4, is expressed by eutopic endometrium only in the menstrual phase. Fertility and Sterility 91 343-349. (https://doi.org/10.1016/j.fertnstert.2007.12.005)
Kennedy S, Bergqvist A, Chapron C, D'Hooghe T, Dunselman G, Greb R, Hummelshoj L, Prentice A, Saridogan E \& ESHRE Special Interest Group for Endometriosis and Endometrium Guideline Development Group 2005 ESHRE guideline for the diagnosis and treatment of endometriosis. Human Reproduction 20 2698-2704. (https://doi.org/10.1093/humrep/ dei135)

Kilic S, Evsen M, Tasdemir N, Yilmaz N, Yuksel B, Dogan M \& Batioglu S 2007 Follicular fluid vascular endothelial growth factor and tumour necrosis factor alpha concentrations in patients with endometriosis undergoing ICSI. Reproductive Biomedicine Online 15 316-320. (https:// doi.org/10.1016/S1472-6483(10)60345-8)

Kollmann Z, Schneider S, Fux M, Bersinger NA \& von Wolff M 2017 Gonadotrophin stimulation in IVF alters the immune cell profile in follicular fluid and the cytokine concentrations in follicular fluid and serum. Human Reproduction 32 820-831. (https://doi.org/10.1093/ humrep/dex005)

Krizan J, Cuchalova L, Sima P, Kralickova M, Madar J \& Vetvicka V 2009 Altered distribution of NK and NKT cells in follicular fluid is associated with IVF outcome. Journal of Reproductive Immunology 82 84-88. (https://doi.org/10.1016/j.jri.2009.05.005)

Lachapelle MH, Hemmings R, Roy DC, Falcone T \& Miron P 1996 Flow cytometric evaluation of leukocyte subpopulations in the follicular fluids of infertile patients. Fertility and Sterility 65 1135-1140. (https://doi. org/10.1016/s0015-0282(16)58327-7)

Lessey BA, Lebovic DI \&Taylor RN 2013 Eutopic endometrium in women with endometriosis: Ground Zero for the study of implantation defects. Seminars in Reproductive Medicine 31 109-124. (https://doi. org/10.1055/s-0032-1333476)

Lukassen HG, van der Meer A, van Lierop MJ, Lindeman EJ, Joosten I \& Braat DD 2003 The proportion of follicular fluid CD16+CD56DIM NK cells is increased in IVF patients with idiopathic infertility. Journal of Reproductive Immunology 60 71-84. (https://doi.org/10.1016/S01650378(03)00081-0)

Mach P, Blecharz P, Basta P, Marianowski P, Skret-Magierlo J, Kojs Z, Grabiec M \& Wicherek L 2010 Differences in the soluble HLA-G blood serum concentration levels in patients with ovarian cancer and ovarian and deep endometriosis. American Journal of Reproductive Immunology 63 387-395. (https://doi.org/10.1111/j.1600-0897.2009.00806.x)

Nagy RA, van Montfoort AP, Dikkers A, van Echten-Arends J, Homminga I, Land JA, Hoek A \& Tietge UJ 2015 Presence of bile acids in human follicular fluid and their relation with embryo development in modified natural cycle IVF. Human Reproduction 30 1102-1109. (https://doi. org/10.1093/humrep/dev034)

Olkowska-Truchanowicz J, Bocian K, Maksym RB, Bialoszewska A, Wlodarczyk D, Baranowski W, Zabek J, Korczak-Kowalska G \& Malejczyk J 2013 CD4(+) CD25(+) FOXP3(+) regulatory T cells in peripheral blood and peritoneal fluid of patients with endometriosis. Human Reproduction 28 119-124. (https://doi.org/10.1093/humrep/ des346)

Opøien HK, Fedorcsak P, Polec A, Stensen MH, Åbyholm T \& Tanbo T 2013 Do endometriomas induce an inflammatory reaction in nearby follicles? Human Reproduction 28 1837-1845. (https://doi.org/10.1093/ humrep/det087)

Ouji-Sageshima N, Yuui K, Nakanishi M, Takeda N, Odawara Y, Yamashita M, Iwayama $\mathrm{H}$, Awai $\mathrm{K}$, Hashimoto $\mathrm{H}$, Geraghty DE et al. 2016 sHLA-G and sHLA-I levels in follicular fluid are not associated with successful implantation. Journal of Reproductive Immunology 113 16-21. (https://doi.org/10.1016/j.jri.2015.10.001)

Pellicer A, Albert C, Mercader A, Bonilla-Musoles F, Remohí J \& Simón C 1998 The follicular and endocrine environment in women with endometriosis: local and systemic cytokine production. Fertility and Sterility 70 425-431. (https://doi.org/10.1016/s0015-0282(98)00204-0)

Pencovich N, Luk J, Hantisteanu S, Hornstein MD \& Fainaru O 2014 The development of endometriosis in a murine model is dependent on the presence of dendritic cells. Reproductive Biomedicine Online 28 515-521. (https://doi.org/10.1016/j.rbmo.2013.12.011)

Podgaec S, Abrao MS, Dias JA, Rizzo LV, de Oliveira RM \& Baracat EC 2007 Endometriosis: an inflammatory disease with a Th2 immune response component. Human Reproduction 22 1373-1379. (https://doi. org/10.1093/humrep/del516)

Podgaec S, Rizzo LV, Fernandes LF, Baracat EC \& Abrao MS 2012 CD4(+) CD25(high) Foxp3(+) cells increased in the peritoneal fluid of patients 
with endometriosis. American Journal of Reproductive Immunology 68 301-308. (https://doi.org/10.1111/j.1600-0897.2012.01173.x)

Qin L, Xu W, Li X, Meng W, Hu L, Luo Z, Wang Y, Luo S \& Li S 2016 Differential expression profile of immunological cytokines in local ovary in patients with polycystic ovarian syndrome; analysis by flow cytometry. European Journal of Obstetrics, Gynecology, and Reproductive Biology 197 136-141. (https://doi.org/10.1016/j. ejogrb.2015.12.003)

Rached MR, Coelho V, Marin MLC, Pincerato K, Fujita A, Kalil JE \& AbrÃo MS 2019 HLA-G is upregulated in advanced endometriosis. European Journal of Obstetrics, Gynecology, and Reproductive Biology 235 36-41. (https://doi.org/10.1016/j.ejogrb.2019.01.030)

Rizzo R, Stignani M, Melchiorri L \& Baricordi OR 2009 Possible role of human leukocyte antigen-G molecules in human oocyte/embryo secretome. Human Immunology 70 970-975. (https://doi.org/10.1016/j. humimm.2009.07.020)

Runesson E, Ivarsson K, Janson PO \& Brannstrom M 2000 Gonadotropinand cytokine-regulated expression of the chemokine interleukin 8 in the human preovulatory follicle of the menstrual cycle. Journal of Clinical Endocrinology and Metabolism 85 4387-4395. (https://doi.org/10.1210/ jcem.85.11.6954)

Sabbaghi M, Aram R, Roustaei H, Fadavi Islam M, Daneshvar M, Castano AR \& Haghparast A 2014 IL-17A concentrations of seminal plasma and follicular fluid in infertile men and women with various clinical diagnoses. Immunological Investigations 43 617-626. (https:// doi.org/10.3109/08820139.2014.909453)

Sallusto F 2013 DCs: a dual bridge to protective immunity. Nature Immunology 14 890-891. (https://doi.org/10.1038/ni.2693)

Sampson JA 1927 Peritoneal endometriosis due to the menstrual dissemination of endometrial tissue into the peritoneal cavity. American Journal of Obstetrics and Gynecology 14 422-469. (https://doi. org/10.1016/S0002-9378(15)30003-X)

Shaikly VR, Morrison IE, Taranissi M, Noble CV, Withey AD, Cherry RJ, Blois SM \& Fernandez N 2008 Analysis of HLA-G in maternal plasma, follicular fluid, and preimplantation embryos reveal an asymmetric pattern of expression. Journal of Immunology 180 4330-4337. (https:// doi.org/10.4049/jimmunol.180.6.4330)

Sica A \& Mantovani A 2012 Macrophage plasticity and polarization: in vivo veritas. Journal of Clinical Investigation 122 787-795. (https://doi. org/10.1172/JCI59643)

Singh AK, Dutta M, Chattopadhyay R, Chakravarty B \& Chaudhury K 2016 Intrafollicular interleukin-8, interleukin-12, and adrenomedullin are the promising prognostic markers of oocyte and embryo quality in women with endometriosis. Journal of Assisted Reproduction and Genetics 33 1363-1372. (https://doi.org/10.1007/s10815-016-0782-5)

Smith MP, Flannery GR, Randle BJ, Jenkins JM \& Holmes CH 2005 Leukocyte origin and profile in follicular aspirates at oocyte retrieval. Human Reproduction 20 3526-3531. (https://doi.org/10.1093/humrep/ dei240)

Somigliana E, Vigano P, Benaglia L, Busnelli A, Berlanda N \& Vercellini P 2017 Management of Endometriosis in the infertile patient. Seminars in Reproductive Medicine 35 31-37. (https://doi. org/10.1055/s-0036-1597125)

Stanic AK, Kim M, Styer AK \& Rueda BR 2014 Dendritic cells attenuate the early establishment of endometriosis-like lesions in a murine model. Reproductive Sciences 21 1228-1236. (https://doi. org/10.1177/1933719114525267)

Takaya R, Fukaya T, Sasano H, Suzuki T, Tamura M \& Yajima A 1997 Macrophages in normal cycling human ovaries; immunohistochemical localization and characterization. Human Reproduction 12 1508-1512. (https://doi.org/10.1093/humrep/12.7.1508)

Tariverdian N, Siedentopf F, Rucke M, Blois SM, Klapp BF, Kentenich H \& Arck PC 2009 Intraperitoneal immune cell status in infertile women with and without endometriosis. Journal of Reproductive Immunology 80 80-90. (https://doi.org/10.1016/j.jri.2008.12.005)

Tsudo T, Harada T, Iwabe T, Tanikawa M, Nagano $Y$, Ito M, Taniguchi F \& Trakawa N 2000 Altered gene expression and secretion of interleukin-6 in stromal cells derived from endometriotic tissues. Fertility and Sterility 73 205-211. (https://doi.org/10.1016/s0015-0282(99)00496-3)

Vujisic S \& Zidovec S 2005 Follicular immunology environment and the influence on in vitro fertilization outcome. Current Women's Health Reviews 1 49-60. (https://doi.org/10.2174/1573404052950258)

Vujisic S, Lepej SZ, Aksamija A, Jerkovic L, Sokolic B, Kupesic S \& Vince A 2004 B- and T-cells in the follicular fluid and peripheral blood of patients undergoing IVF/ET procedures. American Journal of Reproductive Immunology 52 379-385. (https://doi.org/10.1111/j.1600-0897.200 4.00238.x)

Wan YY 2010 Multi-tasking of helper T cells. Immunology 130 166-171. (https://doi.org/10.1111/j.1365-2567.2010.03289.x)

Wu R, Van der Hoek KH, Ryan NK, Norman RJ \& Robker RL 2004 Macrophage contributions to ovarian function. Human Reproduction Update 10 119-133. (https://doi.org/10.1093/humupd/dmh011)

Wu R, Fuiji S, Ryan NK, Van der Hoek KH, Jasper MJ, Sini I, Robertson SA, Robker RL \& Norman RJ 2007 Ovarian leucocyte distribution and cytokine/chemokine mRNA expression in follicular fluid cells in women with polycystic ovary syndrome. Human Reproduction 22 527-535. (https://doi.org/10.1093/humrep/del371)

Wu G, Bersinger NA, Mueller MD \& von Wolff M 2017 Intrafollicular inflammatory cytokines but not steroid hormone concentrations are increased in naturally matured follicles of women with proven endometriosis. Journal of Assisted Reproduction and Genetics 34 357-364. (https://doi.org/10.1007/s10815-016-0865-3)

Wunder DM, Mueller MD, Birkhäuser MH \& Bersinger NA 2006 Increased ENA-78 in the follicular fluid of patients with endometriosis. Acta Obstetricia et Gynecologica Scandinavica 85 336-342. (https://doi. org/10.1080/00016340500501715)

Xu H, Schultze-Mosgau A, Agic A, Diedrich K, Taylor RN \& Hornung D 2006 Regulated upon activation, normal T cell expressed and secreted (RANTES) and monocyte chemotactic protein 1 in follicular fluid accumulate differentially in patients with and without endometriosis undergoing in vitro fertilization. Fertility and Sterility 86 1616-1620. (https://doi.org/10.1016/j.fertnstert.2006.05.043)

Zhang T, Tian F, Huo R, Tang A, Zeng Y \& Duan YG 2017a Detection of dendritic cells and related cytokines in follicular fluid of patients with polycystic ovary syndrome. American Journal of Reproductive Immunology 78 e12717. (https://doi.org/10.1111/aji.12717)

Zhang QF, Chen GY, Liu Y, Huang HJ \& Song YF 2017b Relationship between resistin and IL-23 levels in follicular fluid in infertile patients with endometriosis undergoing IVF-ET. Advances in Clinical and Experimental Medicine 26 1431-1435. (https://doi.org/10.17219/acem/41149)

Zhang T, De Carolis C, Man GCW \& Wang CC 2018 The link between immunity, autoimmunity and endometriosis: a literature update. Autoimmunity Reviews 17 945-955. (https://doi.org/10.1016/j. autrev.2018.03.017)

Zollner KP, Hofmann T \& Zollner U 2013 Good fertilization results associated with high IL-1beta concentrations in follicular fluid of IVF patients. Journal of Reproductive Medicine 58 485-490.

Received 5 February 2019

First decision 7 March 2019

Revised manuscript received 3 June 2019

Accepted 29 July 2019 